\title{
URBAN SPACE CHANGE AND FUTURE PREDICTION OF KANPUR NAGAR, UTTAR PRADESH USING EO DATA
}

\author{
Shubham Sharma ${ }^{1}$, Suraj Kumar Singh ${ }^{2}$, Shruti Kanga ${ }^{1}$, Nikola Kranjčić ${ }^{3^{*}}$, Bojan Đurin ${ }^{4}$ \\ ${ }^{1}$ Centre for Climate Change and Water Research, Suresh Gyan Vihar University, Jaipur 302017, India \\ ${ }^{2}$ Centre for Sustainable Development, Suresh Gyan Vihar University, Jaipur 302017, India \\ ${ }^{3}$ Faculty of Geotechnical Engineering, University of Zagreb, 42000 Varaždin, Croatia \\ ${ }^{4}$ Department of Civil Engineering, University North, 42000 Varaždin, Croatia \\ *E-mail of corresponding author: nikola.kranjcic@gfv.unizg.hr
}

\begin{abstract}
Urban Land use changes, measurements, and the analysis of rate trends of growth would help in resources management and planning, etc. In this study, we analyze the urban change dynamics using a support vector machine model. This method derives the urban and rural land-use change and various components, such as population growth, built-up areas, and other utilities. Urban growth increases rapidly due to exponential growth of population, industrial growth, etc. The population growth also affects the availability of various purposes in its spatial distribution. In this present study, we carried out using multi-temporal satellite remote sensing data Landsat MSS (Multispectral scanner), ETM+ (Enhanced thematic mapper), OLI (Operational land imager) for the analysis of urban change dynamics between years 1980-1990, 1990-2003, 2012-2020 in Kanpur Nagar city in the state of Uttar Pradesh in India. In our study, we used SVM (Support Vector Machine) Model to analyze the urban change dynamics. A support vector machine classification technique was applied to generate the LULC maps using Landsat images of the years 1980, 1990, 2003, and 2020. Envi and ArcGIS software had used to identify the land cover changes and the applying urban simulation model (CA-Markov model) in Idrisi selva edition 17.0 software. The LULC maps of 2003 and 2020 were used to simulate the LULC projected map for 2050 using (Cellular automata) CA-Markov based simulation model.
\end{abstract}

Keywords: Urban growth, Support vector machine, Change detection, Urban simulation model, and CA-Markov model.

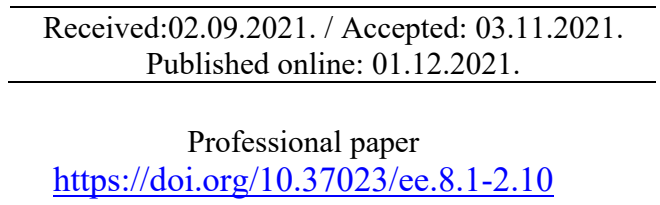

\section{INTRODUCTION}

According to Clark (1982), urban growth is a demographic and spatial process which refers to the increased importance of town and cities with dense population within a specific type of economy and society. Urban land covers about $2 \%$ or $3 \%$ of the earth's land surface (Poelmans and van Rompaey 2010). Therefore, the relevant information by urban planners and scholars to evaluate the intensity and future direction of urban expansion is essential. Hence to monitor, analyze and identify urban expansion initially, satellite images are used.

India, a highly developing country, and a country with high developing nature the people migrate from rural to urban on a large scale, and hence the urban growth is very high. The era of 1970s and 1950, when industrial revolution and globalization respectively were at a boom and had provided India momentum for urbanization. Due to rapidly growing urbanization in India especially in 'megacities' the lifestyle of normal human beings has been improved. But because of rapidly growing urbanization, it has created many problems which include ecological unbalance, loss of agricultural land, pollution, increase in temperature, etc. These types of problems can be solved by requiring information at various levels, such as population growth patterns, local housing patterns, etc. However, these solutions can only be analysed by the proper channel between new technologies and in-situ observations. All the traditional methods can help us in gathering demographic data, census data, and other required information for mapping urban growth. But these methods and techniques may not be relevant for modern urban management.

The population growth, migration, and development of basic infrastructures caused by urbanization and such growth led to the development of hamlet into villages, villages into towns, towns into cities, and cities into megacities. Identification of urban growth knowledge of extent and pattern of growth is required to make development with well-planned infrastructure. All these development techniques require the use of geospatial spatial techniques such as Remote Sensing, Geographic Information systems (GIS), and Global Positioning Systems (GPS). To detect the change in the recent decades remote sensing data are being used in a large amount. With the help of satellite images, we can view the large area at a specific period this cannot be done by any other conventional method. Remote Sensing and Geographic Information System (GIS) were used in mapping urban change dynamics to detect the changes that had taken place during a time. Remote sensing is the science of obtaining information about objects or phenomena without making physical contact with them. 
In this research, the aim to analyse the urban change dynamics using a support vector machine classifier. Support Vector Machine classifiers are being used for analysing the urban change dynamics. One of the Machine Learning techniques that are being used by many researchers in the geospatial analysis is known as a Support Vector Machine which works on statistical learning theory data and formalizing these data.

Machine Learning is a type of learning in which a system is programmed in such a way that it learns and improves automatically by gaining experience. Learning refers to understating and recognizing the supplied data and making a wise decision based on the data provided. There are different types of algorithms used in machine learning to handle various types of problems such as deciding on various types of input provided. By using statistics, probability theory, logic, combinatorial optimization, search, reinforcement learning, and control theory algorithms take the specific data and analysis experience to build knowledge.

Machine learning can be used in many places and can appear in day-to-day life. Machine learning is an art of learning in which a group of data is supplied and based on some algorithm a fairly set of prototypes are provided to us. Support vector machines are a great example of machine learning which works on analysing data and recognizing patterns.

\section{STUDY AREA}

\subsection{Location and size}

Kanpur Nagar is located on the Ganga and Yamuna doab track. It is situated on the Ganga's bank. It is located between the latitudes of $25^{\circ} 26^{\prime}$ and $26^{\circ} 58^{\prime}$ north, and the longitude of $79^{\circ} 31^{\prime}$ and $80^{\circ} 34^{\prime}$ east. It is bounded in the north by the districts of kanuuaj and Hardoi, in the east by the district of Unnao, in the south by the district of Fatehpur and Hamirpur, and in the west by the district of Kanpur dehat. It is divided from district Unnao in the east by the holy Ganga River, which serves as a natural barrier. It is separated from the districts Kanpur dehat and Fatehpur in the west and south, respectively, by the Pandu River.

\subsection{Demography}

According to census 2011 Kanpur had a population of 4,581,268 in 2011 with 2,459,809 males and 2,121,462 females. Kanpur Nagar had a population of 4,167,999 in the 2001 census with 2,247,216 males and 1,920,783 females. When compared to the population in 2001, there was a 9.92 percent change. In comparison to the population in 2001, there was a 9.92 percent increase in the population. According to the previous census of India 2001, Kanpur Nagar's population recorded increased by 28.11 percent compared to 1991 .

\subsection{Physiography}

The district of Kanpur Nagar is in the middle Ganga plain- west, which covers an area of 1,065 sq. km. The Ganga's course is a wide and sandy bed that changes on occasion. A belt is formed by new alluvium deposits, in addition to sand. Alluvium deposits are mostly found above flood level and are referred to as 'kachhar'. Many ravines are formed by the high cliffs that run along the Ganga. The Pandu and Rind rivers both flow through the district. Geologically, the district is made up of alluvium and recent Dun gravels. The district has been divided into some sub-micro-regions based on geology, soils, topography, climate, and natural vegetation (likes- Ganga khaddar, Kanpur plain, Rind plain).

\subsection{Drainage}

The two major rivers of the district are Ganga and the Yamuna. The Isan and Non are Ganga tributaries, and the Rind is the major Yamuna tributary. Pandu is the next significant river.

The Ganga enters the village of Chita Mau and flows along the district's northeast boundary for its entire length, skirting the tehsils of Bilhaur and Kanpur. It has a broad and sandy belt that changes its channel almost as its sandbanks form and is washed away. When it rains, the Ganga has a huge width, but when it gets cold, it shrinks to much smaller dimensions. The river leaves the district at village Purwa Mir in Kanpur tehsil.

Yamuna River separates the district from Hamirpur in the south and flows for almost 58 kilometers from Kanpur in the north.

\subsection{Climate}

The district's climate is characterized by a hot summer and general dryness, except during the monsoon season. The summer season lasts from March to about the middle of June, followed by the monsoon season until the end of September, October, and the first half of November. The cold season lasts from about the middle of November 
to the beginning of February. This climate is classified as Cwa, according to Koppen and Geiger. Kanpur has an average annual temperature of $25.3^{\circ} \mathrm{C} / 77.5^{\circ} \mathrm{F}$.

\subsection{Flora and fauna in Kanpur}

In Kanpur, you can expect to see a lot of migratory birds. These birds are regularly seen in the locations around Bithoor, the Ganges canal, and the IIT campus. In the various parts of the city, peacocks and nilgais can be observed in great numbers. Wolves, chikaras, black bull, hyena, fox, and jackals are among the important wild creatures that can be found in the area. The district, which was once rich in vegetation, is now devoid of it. Flora in the district is limited to patches of Dhak, Babul, Siras, and Termind (Imli). Figure 1 presents location of study area.
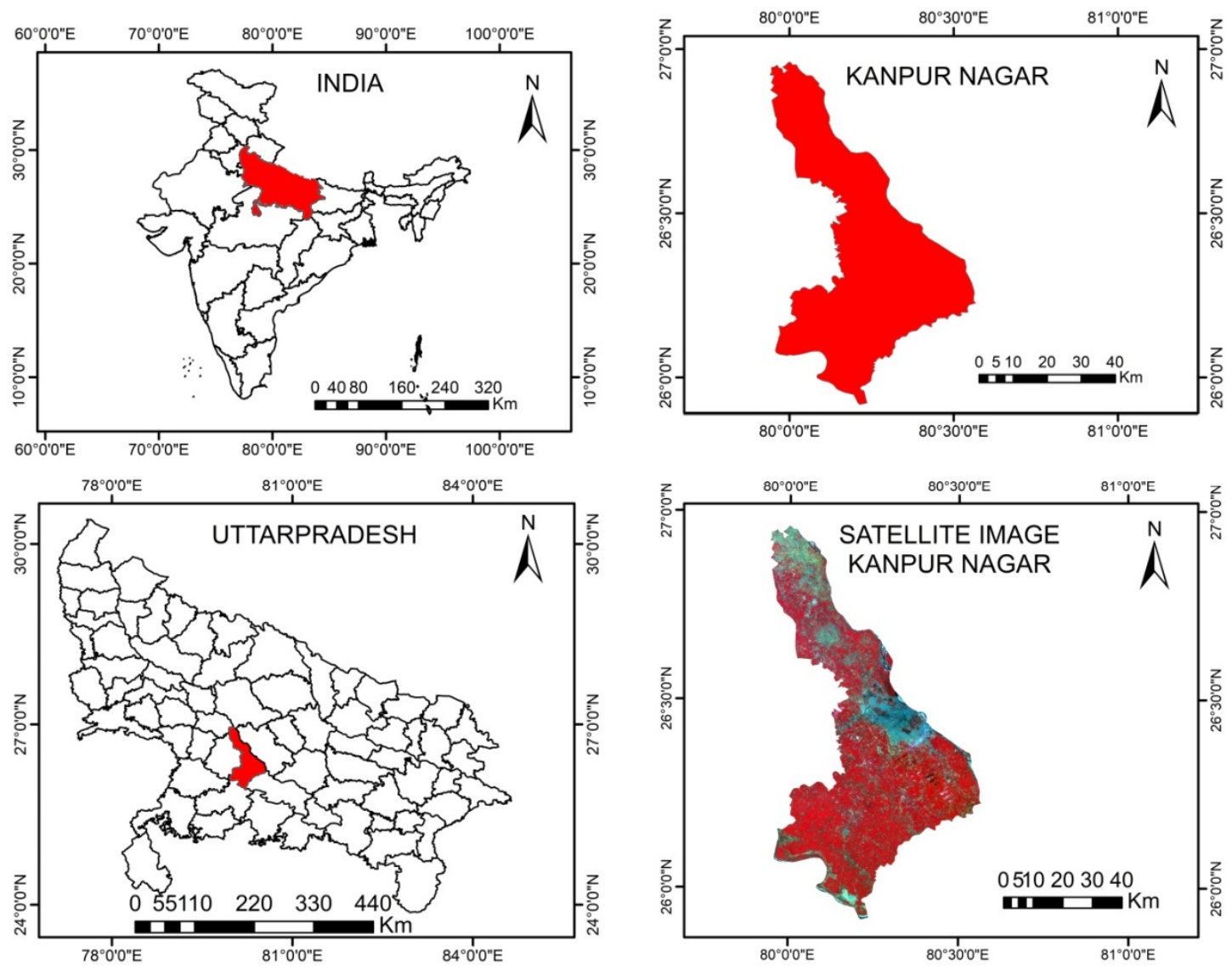

Figure 1. Location map of study area

\section{DATA USED AND METHODOLOGY}

\subsection{Software used}

The task of image correction, pre-processing, and support vector machine classification are done in ENVI 5.3 software. urban changes and using urban simulation model are performed by IDRISI Selva 17. The preparation of various data layer maps is carried out in ArcGIS 10.6. For Ground Validation: Google Earth

\subsection{Data used}

\subsubsection{Raster data}

The satellite images are the main sources of data that are used for urban change dynamics. The remote sensed data used in the study area. The images were cloud-free with excellent quality.

In this study, we use Landsat satellite datasets. The Landsat data are the main sources for monitoring and extracting information about urban change dynamics. Landsat datasets are used for modelling urban change dynamics with the help of a support vector machine classifier. With the help of these datasets, spatiotemporal maps are prepared. The Landsat program is series of Earth-observing satellite missions are combined managed by NASA and the U.S Geological survey. On 23 July 1972 the Earth Resources Technology (ERTS-1) Satellite was launched, 
later named was Landsat-1. On March 5, 1978, Landsat 3 MSS was launched. Landsat 7 was launched in 1999 and Landsat 8 was launched on February 11,2013.

The data for the four time periods $(1980,1990,2003$, and 2020) are made availed by the website USGS Earth Explorer.

\subsubsection{Vector data and pre-processing}

The state and district boundaries of Uttar Pradesh and Kanpur city are provided by Data meet open sources. The cardinal step toward the use of remote sensing data for the preparation of the GIS database is to geometrically correct the maps and satellite image data sets. This process has been formed a very important step in the data preparation because formation- temporal datasets and maps of master plans. Pre-processing operations are referred to as image restoration and rectification purposes to correct radiometric and geometric distortions of the data. the research was carried out using Landsat imageries to identify changes in LULC in Landscape changes over 40 periods of 1980 to 2020 years. To observe and discriminate surface features, all the input satellite images were composed using the RGB color composition. The images provided comprehensive coverage of the area of study and layer stacking of bands, mosaicking, and extraction of the image had done using ENVI 5.3 software. The satellite image covers a large area. However, in practice, most of the area in the satellite image is not required for the research, so we extract the study area in satellite images. This step is carried out in ArcGIS 10.6 software. In this study we put the shapefile of Kanpur Nagar boundary overlay on the satellite image then we extract the study area. The primary aim of image enhancement is not to maintain image fidelity. It turns out that image enhancement is used to improve the visual interpretation of images, with the main goals being to improve image definition and contrast, as well as to emphasize the necessary information in the image.

\subsubsection{Classification and support vector machine}

The land use and land cover categorization developed in the classification system presented in this report can be related to a system for classifying land capability, vulnerability to certain management techniques, and potential for any activity or land value, either intrinsic or speculative (Anderson et al., 1976). The method of assigning land cover classes to pixels is known as image classification. For example, classes include urban, forest, water, agriculture, etc. The supervised classification method was used in this thesis. during the supervised classification process, we assign the training sets of the areas and give classes name such as agriculture, vegetation, settlement, and so on.

The Urban dynamics were performed using the Support Vector Machine (SVM). The SVM method was familiarized inside the Context of the Statistical Learning Theory evolved utilizing (Cauwenberghs and Poggio 2001). A Support Vector Machine is a supervised non-parametric statistical learning technique that becomes formerly designed for binary classification (Mathur and Foody, 2008). Support Vector Machine is a very useful method for the classification of remotely sensed data.

SVMs have regularly been found to offer higher classification results than other broadly used sample popularity techniques, including the maximum likelihood and neural network classifiers (Melgani and Bruzzone 2004, Theodoridis and Koutroumbas 2003). The Support Vector Machine is a classifier that detects a hyperplane or a function that divide into two classes with a maximum distance (margin).

\subsubsection{Accuracy assessment}

The easiest way to know the classification result is to check everything in each class, which ENVI could do with the accuracy assessment function. To ensure that the random points were disputed exactly from each class, exactly equal random was used for parameter distribution, and the number of random samples set. A class code in the reference column was assigned to each point on the images, the class value was then displayed to check for agreement. The data was tabulated, and the error matrix was used to describe the finding.

\subsubsection{Factors driving the urban growth and analysis of the future urbanization areas}

The land-use issue is influenced by several geographical factors such as accessibility, proximity, and the physical nature of the land as it exists. The model is based on land parameters within the domains of planning areas delineated by the town and country planning department, with all variables defined within these domains. The urban growth models have some key factors like' road structure (major, minor), railways, airports, built-up, etc. for this key factor we prepared the Distance maps to each factor in the study area. Analysis of the future urbanization areas can be performed based on the two time-period land cover maps for the earlier and later years and feeding them into the Markov chain process. A pair of land cover images are analyzed by the Markov chain method, which produces a transition probability matrix, a transition areas matrix, and a set of conditional probabilities images. The transition probability matrix and transition areas matrix are found in a text file that records the category of the change in other category and numbers of pixels. 


\subsubsection{CA-Markov model}

Both the Markov chain and the CA are discrete dynamics models in time and state. One of Markov's inherent flaws is that it lacks a sense of geography. The transition probabilities may be correct on a per-category basis, but the spatial distribution of occurrences within each land use category is unknown. In this paper, we use Idrisi software to predict land use in this region.

- $\quad$ Land use data of 2020 is specified as a basic image. The transition probabilities area from the years 2003 to 2020 were used for Markov conditional probability matrix

- A CA filter is used to generate a spatial explicit contiguity-weighting factor to change the state of cells based on their neighbours. The filter is a 5 X 5 contiguity filter. Figure $\mathbf{2}$ presents whole methodology workflow.

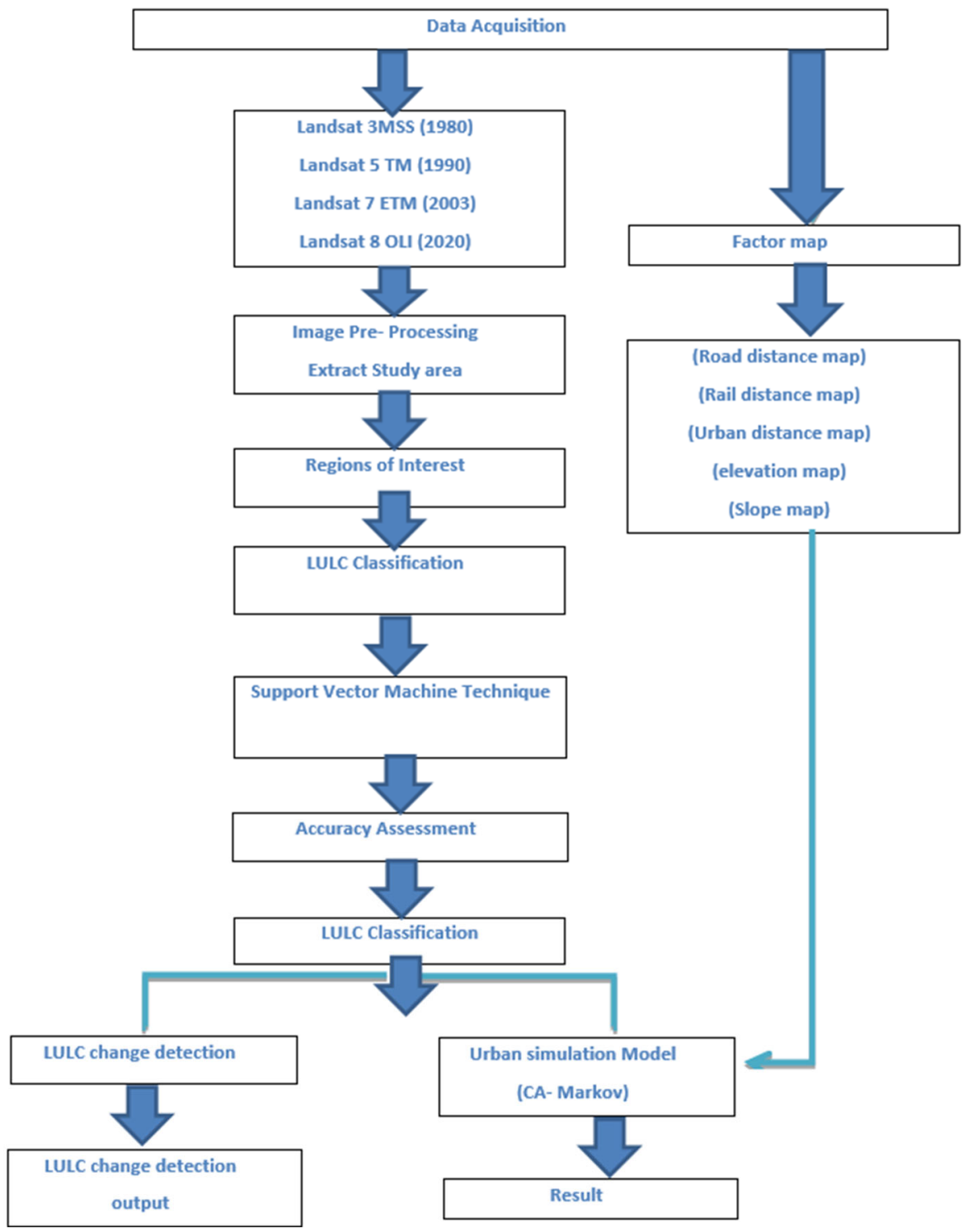

Figure 2. Methodology flowchart

\section{RESULTS AND DISCUSSION}

This research aims to obtain land use and land cover mapping of the Kanpur Nagar District, Uttar Pradesh. In this research, we use a support vector machine classifier for accuracy. After processing the satellite images, the land use and land cover area were analyzed using Support Vector Machine classification. Raster data has been classified and analyzed with different tools in ENVI5.3 software. Figure 3 presents land use and land cover map from 1980. 


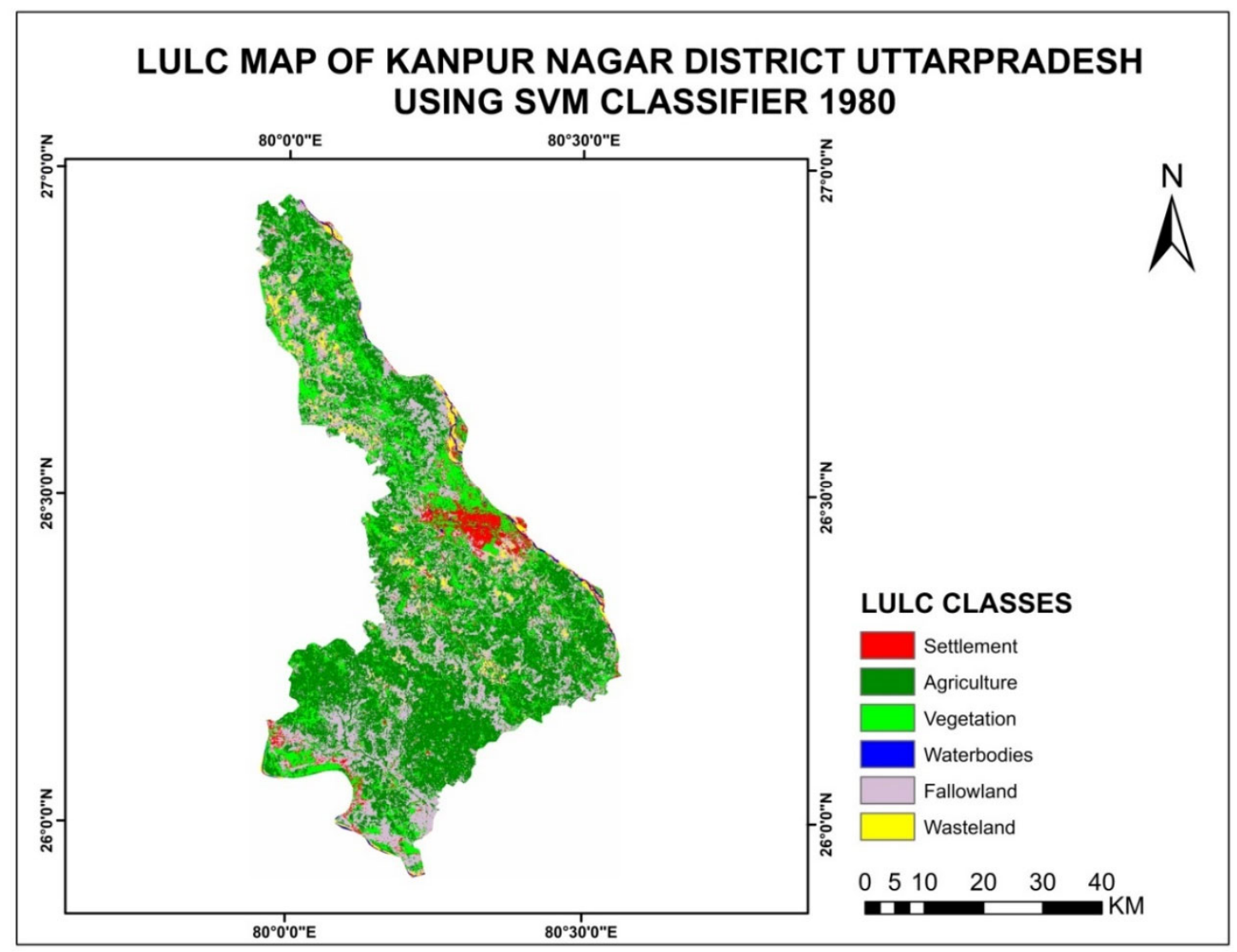

Figure 3. Land use and land cover map in 1980

In the year 1980 , out of the total area of 2877 sq.km, the settlement covered 120 sq.km which is $4.17 \%$ of the total area, whereas a major share of the total area is coved by agricultural land which is $1332 \mathrm{sq}$. km and $46.29 \%$ of the total percentage. $525 \mathrm{sq}$. km area covers by vegetation which is $18.25 \%$ of the total area than water bodies, fallow land, and wasteland cover 12,825 , and $63 \mathrm{sq}$. $\mathrm{km}$, which $0.42 \%, 28.67 \%$, and $2.20 \%$ respectively. The overall accuracy is commonly given as a percentage, with 100 percent accuracy indicating that all references sited were correctly categorized and the overall accuracy is an average and does not provide information about the error between classes. The accuracy of the user essentially informs us how often the class on the map will appear on the ground. This is referred to as trustworthiness. The Commission Error is the complement of the User's Accuracy, so User's Accuracy $=100 \%$ - Commission Error. The user's Accuracy is calculated by dividing the total number of correct classifications for a class by the total number of rows. Producer's Accuracy is the opposite of Omission Error. Producer's Accuracy $=100 \%$ - Omission Error. It's also the number of accurately classified reference sites divided by the total number of reference sites in the class.

Producer and user accuracy of the SVM classified image are given below. Water bodies have the highest producer accuracy and settlement has the lowest producer accuracy. On the other hand, in the case of user accuracy, agriculture has the highest user accuracy, and settlement has the lowest user accuracy. The overall classification accuracies for the year 1980 were $85.48 \%$ and the kappa statistics as $82.377 \%$ respectively. Table 1 presents accuracy assessment for the classification in year 1980 .

Table 1. Accuracy assessment for the classification in 1980

\begin{tabular}{|c|c|c|}
\hline CLASSES & PRODUCER & USER \\
\hline Settlement & $80.70 \%$ & $77.97 \%$ \\
\hline Agriculture & $83.05 \%$ & $92.45 \%$ \\
\hline Vegetation & $81.16 \%$ & $82.35 \%$ \\
\hline Water & $94.44 \%$ & $87.18 \%$ \\
\hline Fallow land & $88.00 \%$ & $89.80 \%$ \\
\hline Wasteland & $93.75 \%$ & $85.71 \%$ \\
\hline
\end{tabular}


Figure 4 shows land use and land cover in year 1990.

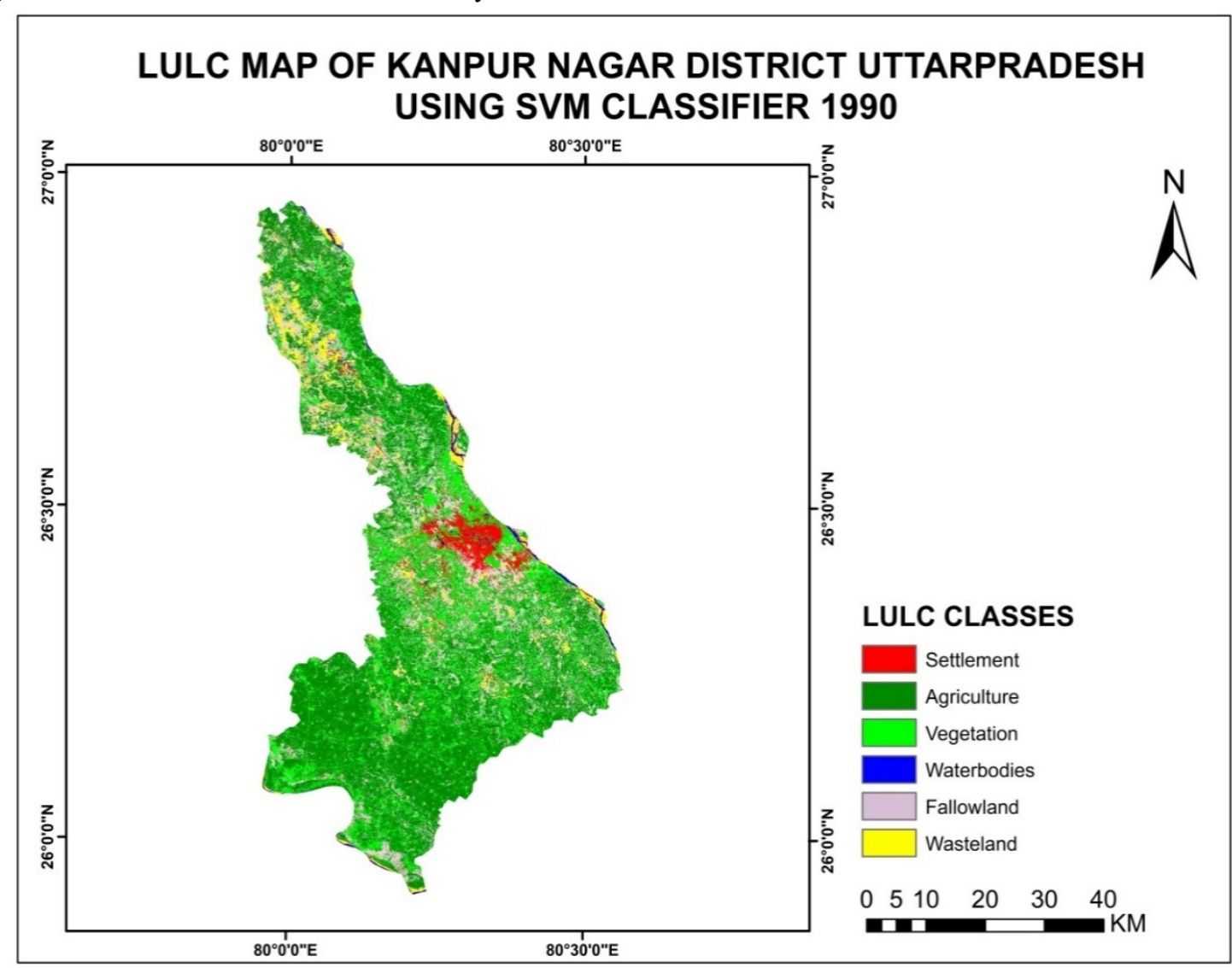

Figure 4. Land use and land cover map in 1990

It is quite evident that there was an increase of $0.82 \%$ in the settlement from 1980 to 1990 . The percentage of settlement rises from 4.17 in 1980 to $5 \%$ in 1990 . A decrease can be seen in agriculture compared to the 1980 due and fallow land increased. The percentage of land cover classed as fallow remained the same.

Producer and user accuracy of the SVM classified image are shown in the Table 2 given below. Agriculture has the highest producer accuracy and water bodies have the lowest producer accuracy. On the other hand, in the case of user accuracy, water bodies have the highest user accuracy, and wasteland has the lowest user accuracy. The overall classification accuracies for the year 1990 were $84.38 \%$ and the kappa statistics as $81.216 \%$ respectively.

Table 2. Accuracy assessment for the classification in 1990

\begin{tabular}{|c|c|c|}
\hline CLASSES & PRODUCER & USER \\
\hline Settlement & $84.78 \%$ & $78.00 \%$ \\
\hline Agriculture & $96.23 \%$ & $78.46 \%$ \\
\hline Vegetation & $78.08 \%$ & $91.94 \%$ \\
\hline Water & $76.47 \%$ & $100.00 \%$ \\
\hline Fallow land & $79.37 \%$ & $84.75 \%$ \\
\hline Wasteland & $95.74 \%$ & $77.59 \%$ \\
\hline
\end{tabular}

Figure 5 presents land use and land cover in year 2003. 


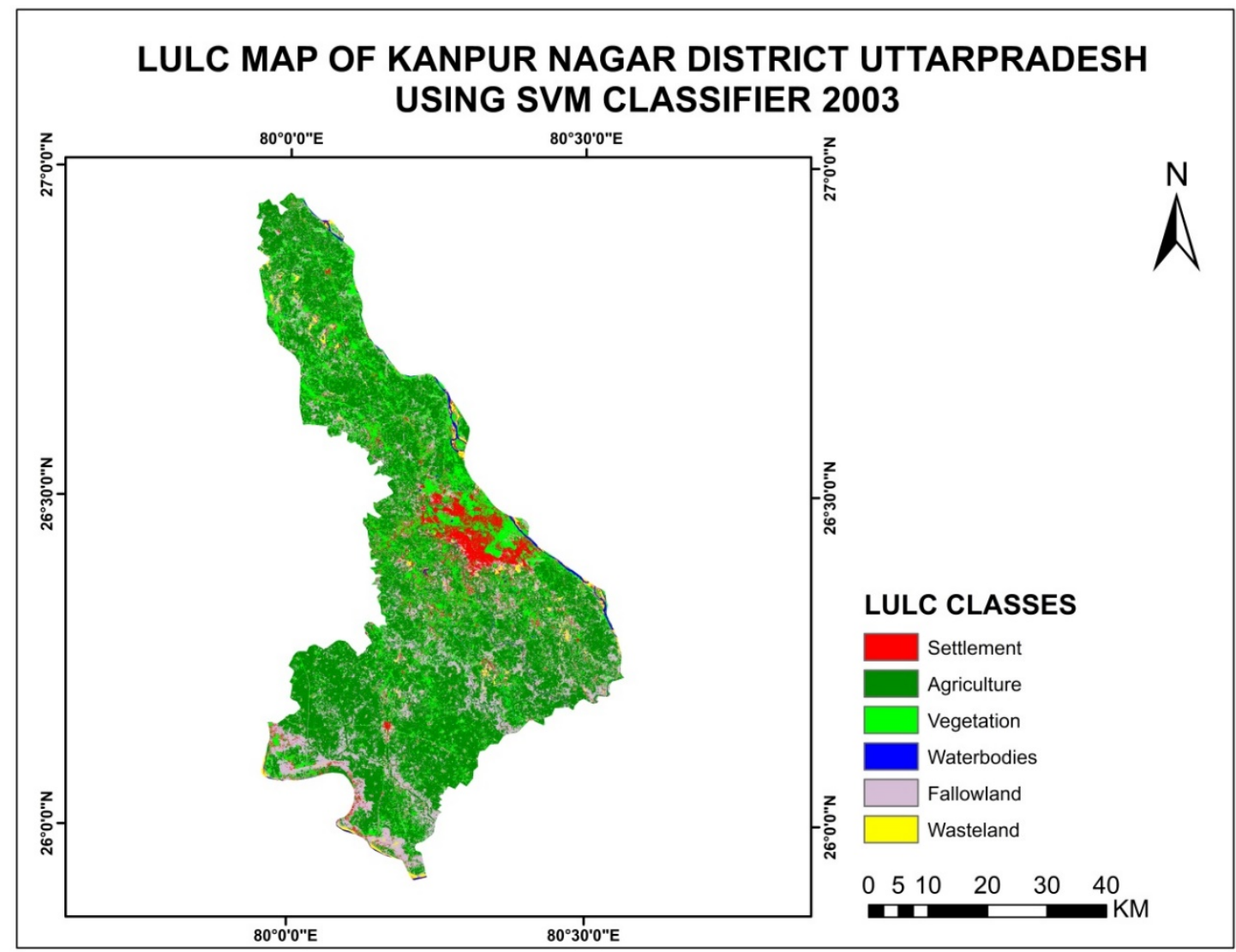

Figure 5. Land use and land cover map in 2003

The land cover map for the year 2003 as shown in Figure 5 clearly shows the growth of the settlement area concerning the previous years. The rapid urbanization in the latest period is attributed to the increasing availability of higher-level facilities, better employability, infrastructure, and industrialization.

In the year 2003 , out of the total area of $2877 \mathrm{sq} . \mathrm{km}$, the settlement covered the $201 \mathrm{sq} . \mathrm{km}$, which is $7.00 \%$ of the total area, whereas a major share of the total area is coved by agricultural land which is $1525 \mathrm{sq} . \mathrm{km}$ and $53.03 \%$ of the total percentage. $536 \mathrm{sq}$. $\mathrm{km}$ area covers by vegetation which is $18.64 \%$ of the total area than water bodies, fallow land, and wasteland covers 29,550 , and 33 sq. km, which $1.01 \%, 19.14 \%$, and 1.18\% respectively.

Producer and user accuracy of the SVM classified image are shown in the Table 3 given below. Wasteland has the highest producer accuracy and settlement has the lowest producer accuracy. On the other hand, in the case of user accuracy, water bodies have the highest user accuracy, and settlement has the lowest user accuracy. The overall classification accuracies for the year 2003 were $86.11 \%$ and the kappa statistics as $83.202 \%$ respectively.

Table 3. Accuracy assessment for the classification in 2003

\begin{tabular}{|c|c|c|}
\hline CLASSES & PRODUCER & USER \\
\hline Settlement & $77.59 \%$ & $83.33 \%$ \\
\hline Agriculture & $93.75 \%$ & $89.55 \%$ \\
\hline Vegetation & $87.93 \%$ & $83.61 \%$ \\
\hline Water & $88.89 \%$ & $93.02 \%$ \\
\hline Fallow land & $79.66 \%$ & $83.93 \%$ \\
\hline Wasteland & $94.87 \%$ & $88.10 \%$ \\
\hline
\end{tabular}

Figure 6 presents land use and land cover in the year 2020. 


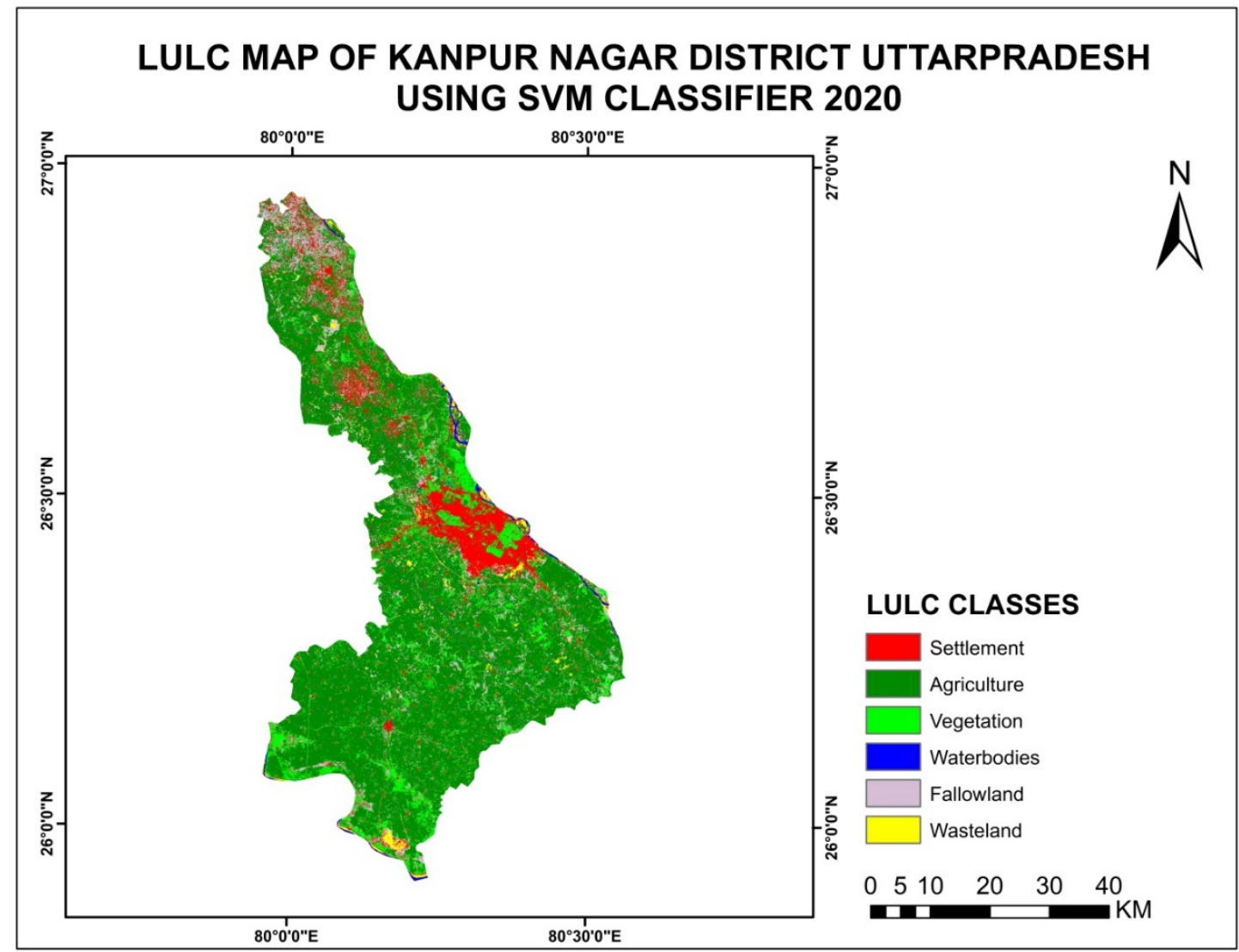

Figure 6. Land use and land cover map in 2020

In the year 2020, out of the total area of 2877 sq. km, the settlement covered $324 \mathrm{sq} . \mathrm{km}$ which is $11.25 \%$ of the total area, whereas a major share of the total area is coved by agricultural land which is $1786 \mathrm{sq}$. km and $62.10 \%$ of the total percentage. $417 \mathrm{sq}$. km area covers by vegetation which is $14.52 \%$ of the total area then water bodies, fallow land, and wasteland cover 29, 272 and $47 \mathrm{sq}$. km, which 1.01\%, 9.47\%, and 1.65\% respectively.

Producer and user accuracy of the SVM classified image are shown in the Table 4 given below. Agriculture has the highest producer accuracy and water bodies have the lowest producer accuracy. On the other hand, in the case of user accuracy, the settlement has the highest user accuracy, and fallow land has the lowest user accuracy. The overall classification accuracies for the year 2020 were $86.11 \%$ and the kappa statistics as $83.202 \%$ respectively.

Table 4. Accuracy assessment for the classification in 2020

\begin{tabular}{|c|c|c|}
\hline CLASSES & PRODUCER & USER \\
\hline Settlement & $89.47 \%$ & $92.73 \%$ \\
\hline Agriculture & $94.00 \%$ & $85.45 \%$ \\
\hline Vegetation & $83.33 \%$ & $86.21 \%$ \\
\hline Water & $81.25 \%$ & $96.30 \%$ \\
\hline Fallow land & $88.64 \%$ & $78.00 \%$ \\
\hline Wasteland & $77.78 \%$ & $81.40 \%$ \\
\hline
\end{tabular}

\subsection{Land use and land cover change detection}

This section shows the result of land use and land cover change detection. The landscape growths in this thesis were monitored using change detection. The changes in the areas from 1980 to 2020 were showing the categorized maps of Kanpur Nagar district. These pie-graph and tables are representing the statics the LULC changes. Figure 7 shows land cover changes from period 1980 to period 1990. 


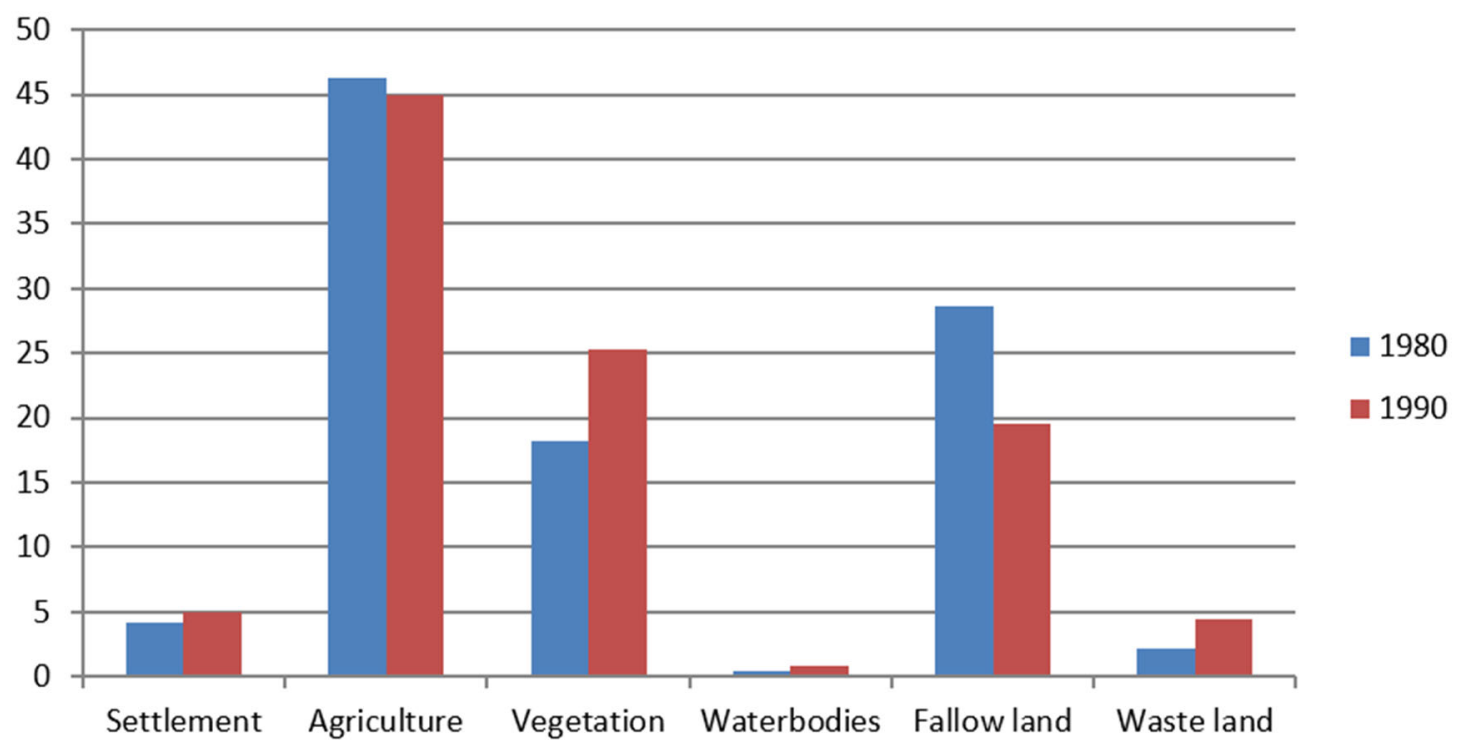

Figure 7. Land cover changes graph 1980 - 1990

From the comparison of Figure 7 for the year 1980-1990, it is quite evident that there were a total increase of 21 sq. $\mathrm{km}$ and $0.82 \%$ in the settlement area and huge changes can be seen in vegetation, the total increment vegetation classes are 7\% and $203 \mathrm{sq} . \mathrm{km}$. agricultural land is decreasing and the fallow land also decrease. In Kanpur mostly bilaur, bithoor, chubepur, Kanpur cantonment and along the major rivers here we found a huge amount of vegetation.

Figure 8 presents land cover changes from year 1990 to 2003

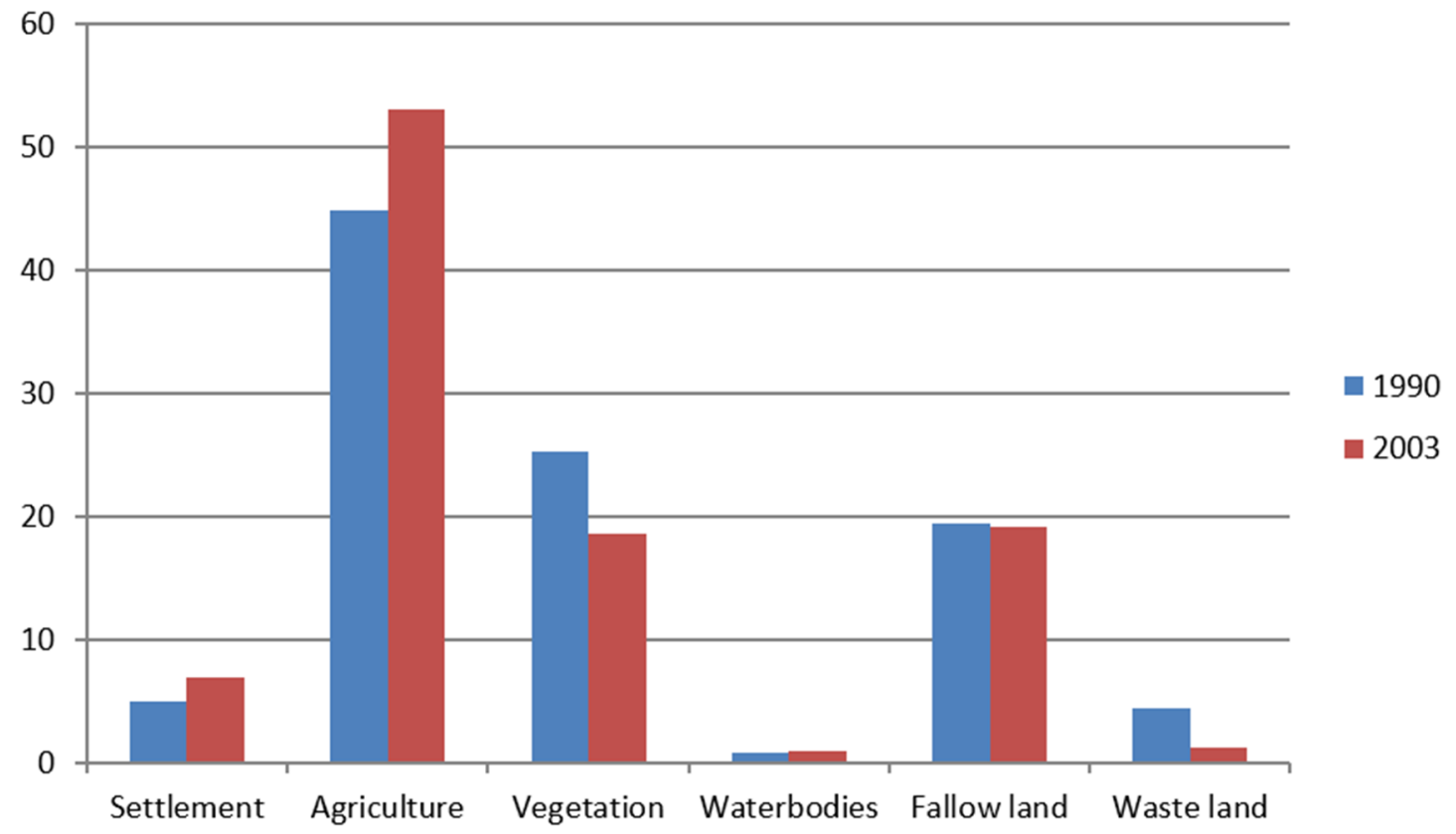

Figure 8. Land cover changes graph 1990 - 2003

In 2003 the settlement area is increased compared to previous years; the settlement increased $58 \mathrm{sq} . \mathrm{km}(2 \%)$. Vegetation area is decreasing 192 sq.km and agriculture are increased 234 sq. km. Figure 9 presents land cover change from year 2003 to year 2020. 


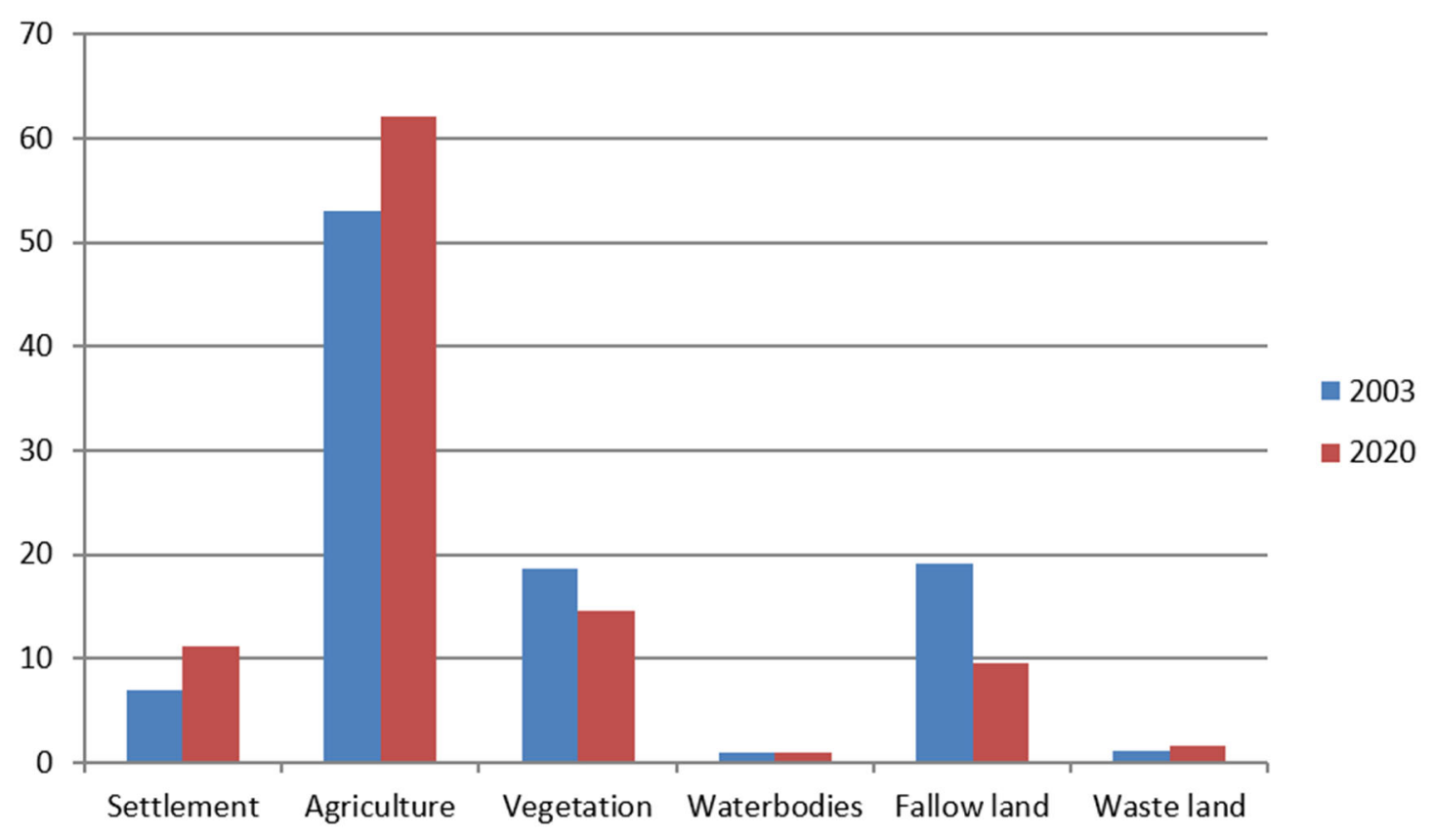

Figure 9. Land cover changes graph 2003 - 2020

The result shows that between 2003 and 2020, approximately $22 \%$ of vegetation and $50 \%$ of fallow land were transformed to other classes. The land cover changes show the latest period increase the utilities, better employability, infrastructure, and industrialization. Many projects are under-processed to make Kanpur a smart city, but most projects are based are only Kanpur urban areas and on the other side Kanpur rural are undeveloped and no found a better infrastructure and better employments. Most people who live in rural areas depend on agriculture.

\subsection{Factor inducing urban growth in the study area}

The result shows that between 2003 and 2020, approximately $22 \%$ of vegetation and $50 \%$ of fallow land were transformed to other classes. The land cover changes show the latest period increase the utilities, better employability, infrastructure, and industrialization. Many projects are under-processed to make Kanpur a smart city, but most projects are based are only Kanpur urban areas and on the other side Kanpur rural are undeveloped and no found a better infrastructure and better employments. Most people who live in rural areas depend on agriculture. Figures 10 - 13 presents as it follows: elevation map, slope map, rail network map and road network map. Table 5 presents probability matrix of possible changes in the future. 


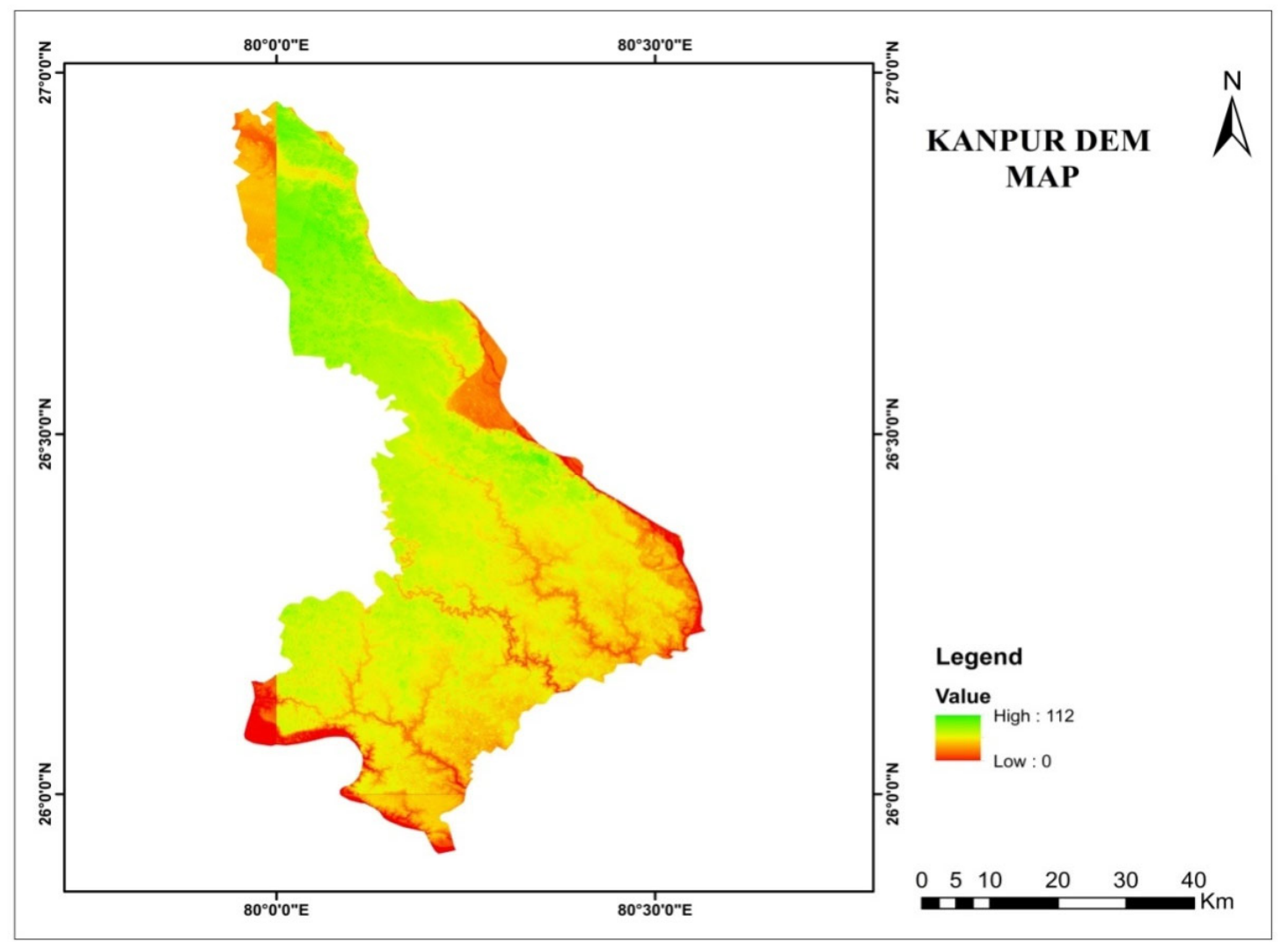

Figure 10. Kanpur elevation map

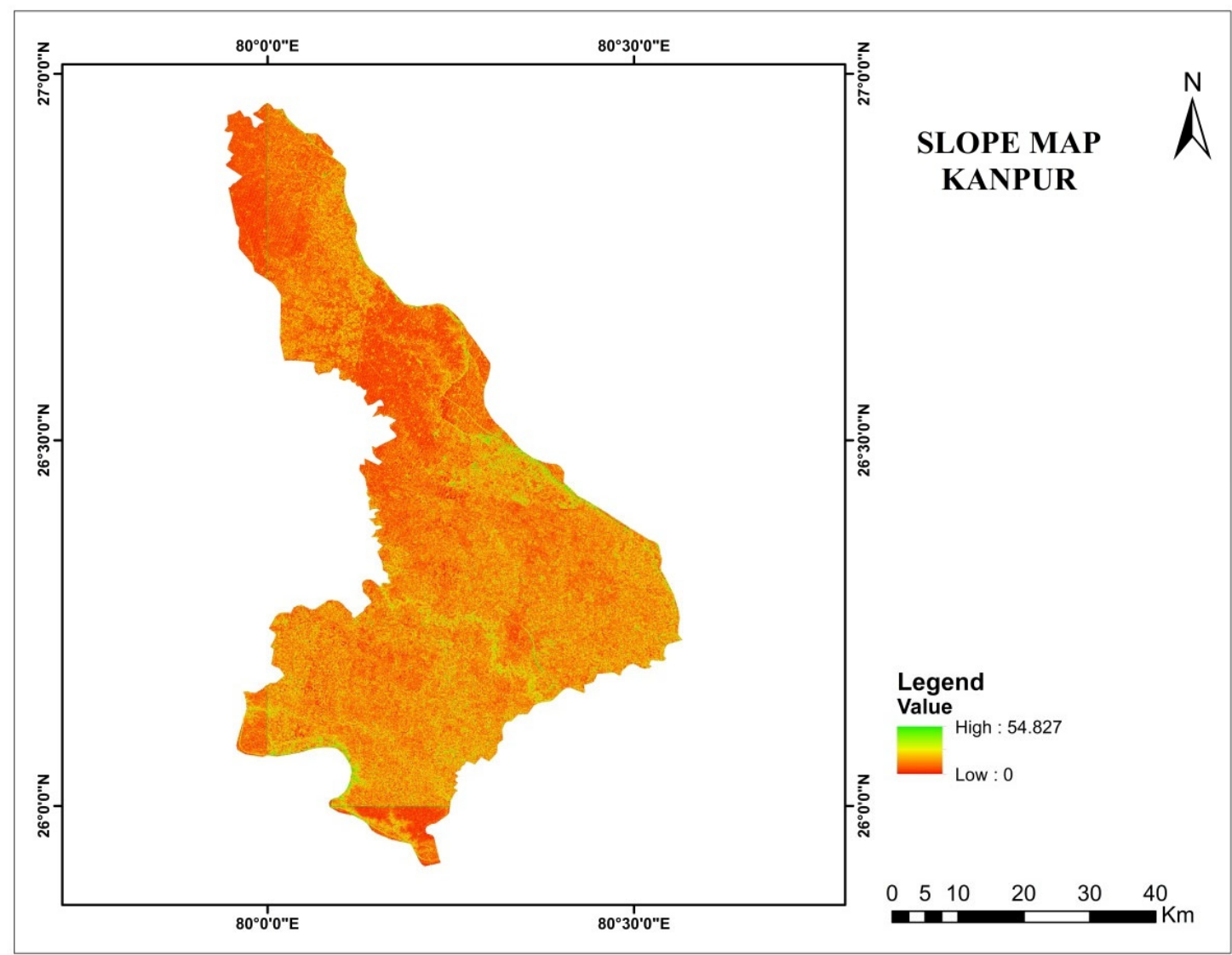

Figure 11. Kanpur slope map 


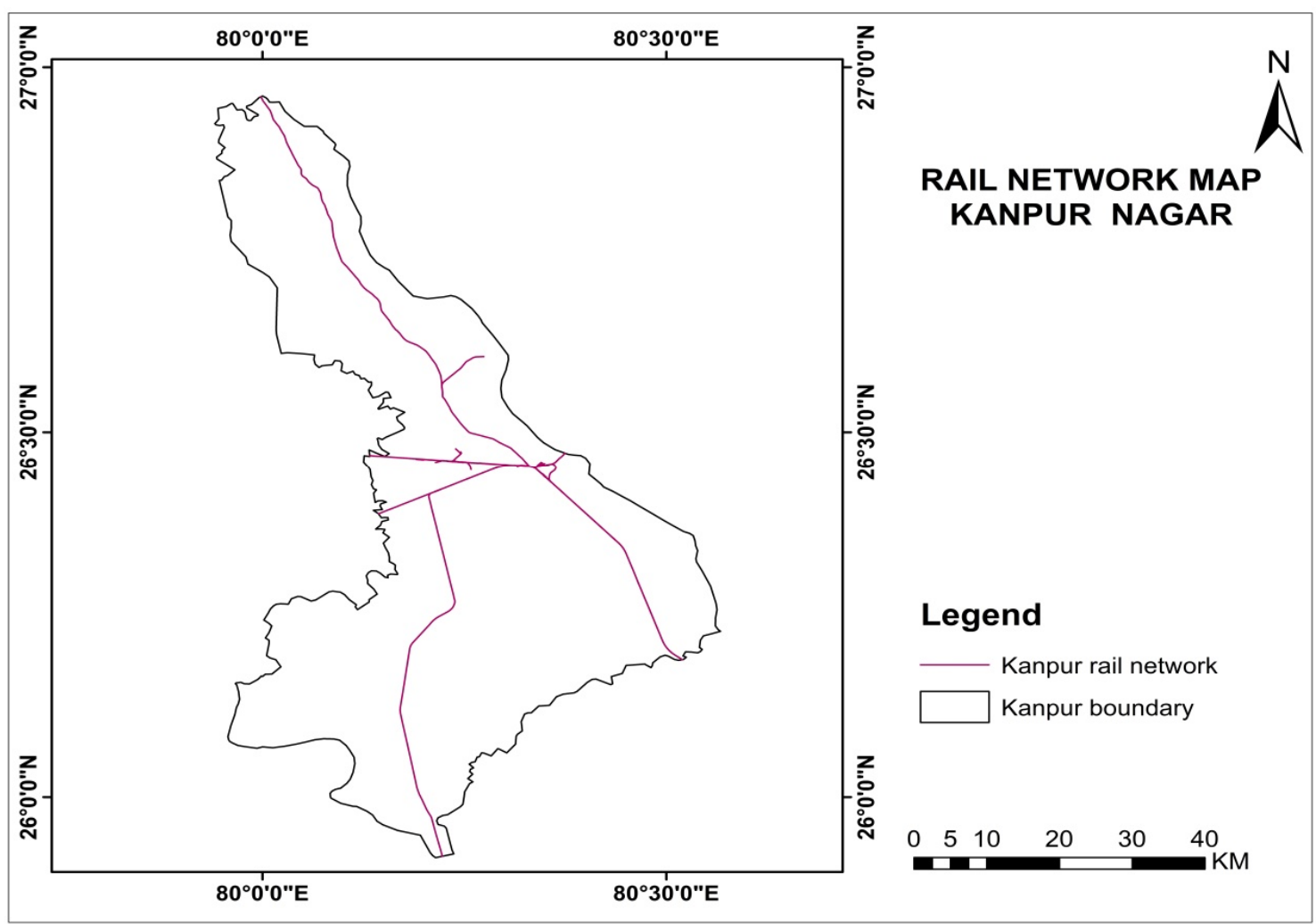

Figure 12. Kanpur rail network map

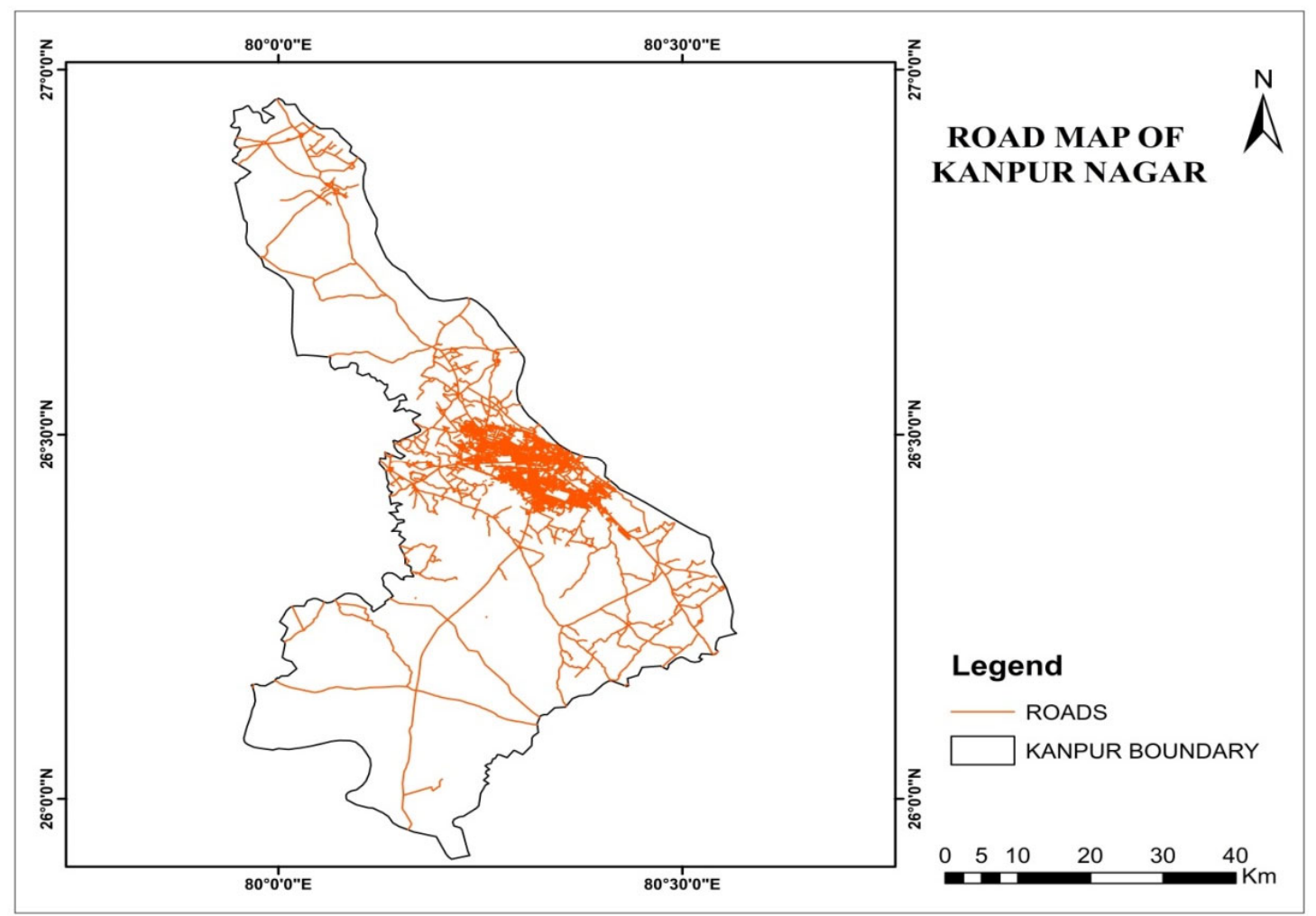

Figure 13. Kanpur road network map 
Table 5. Transition probability matrix

\begin{tabular}{|c|c|c|c|c|c|c|}
\hline CLASSES & 1. Settlement & 2.Agriculture & 3. Vegetation & 4. Water & 5. Fallow land & 6. Wasteland \\
\hline 1. Settlement & 0.23 & 0.50 & 0.16 & 0.02 & 0.07 & 0.02 \\
\hline 2. Agriculture & 0.10 & 0.69 & 0.11 & 0.01 & 0.08 & 0.01 \\
\hline 3. Vegetation & 0.15 & 0.60 & 0.14 & 0.01 & 0.08 & 0.02 \\
\hline 4. Water & 0.16 & 0.49 & 0.18 & 0.02 & 0.08 & 0.03 \\
\hline 5. Fallow land & 0.13 & 0.62 & 0.13 & 0.01 & 0.08 & 0.02 \\
\hline 6. Wasteland & 0.15 & 0.54 & 0.15 & 0.03 & 0.10 & 0.04 \\
\hline
\end{tabular}

The Markov chain calculates the rate of change by comparing earlier and later land cover maps as well as the date specified. The procedure calculates how much land is expected to transition from a later date to the prediction date based on a future projection of transition potentials and generates a transition probability file. The transition probabilities file is a matrix that records the probability that each land cover class will change to other classes. This figure shows the land cover classes change into another class.

Then apply the CA model for generating the future projected land cover map. According to this projected land cover images the settlement increases approximately $437 \mathrm{sq} . \mathrm{km}$ and agriculture, vegetation, water bodies, fallow land, wasteland cover 1728, 388, 29, 252, 42 sq. km of the land. Figure 14 presents projected land use and land cover map for year 2030 of Kanpur Nagar.

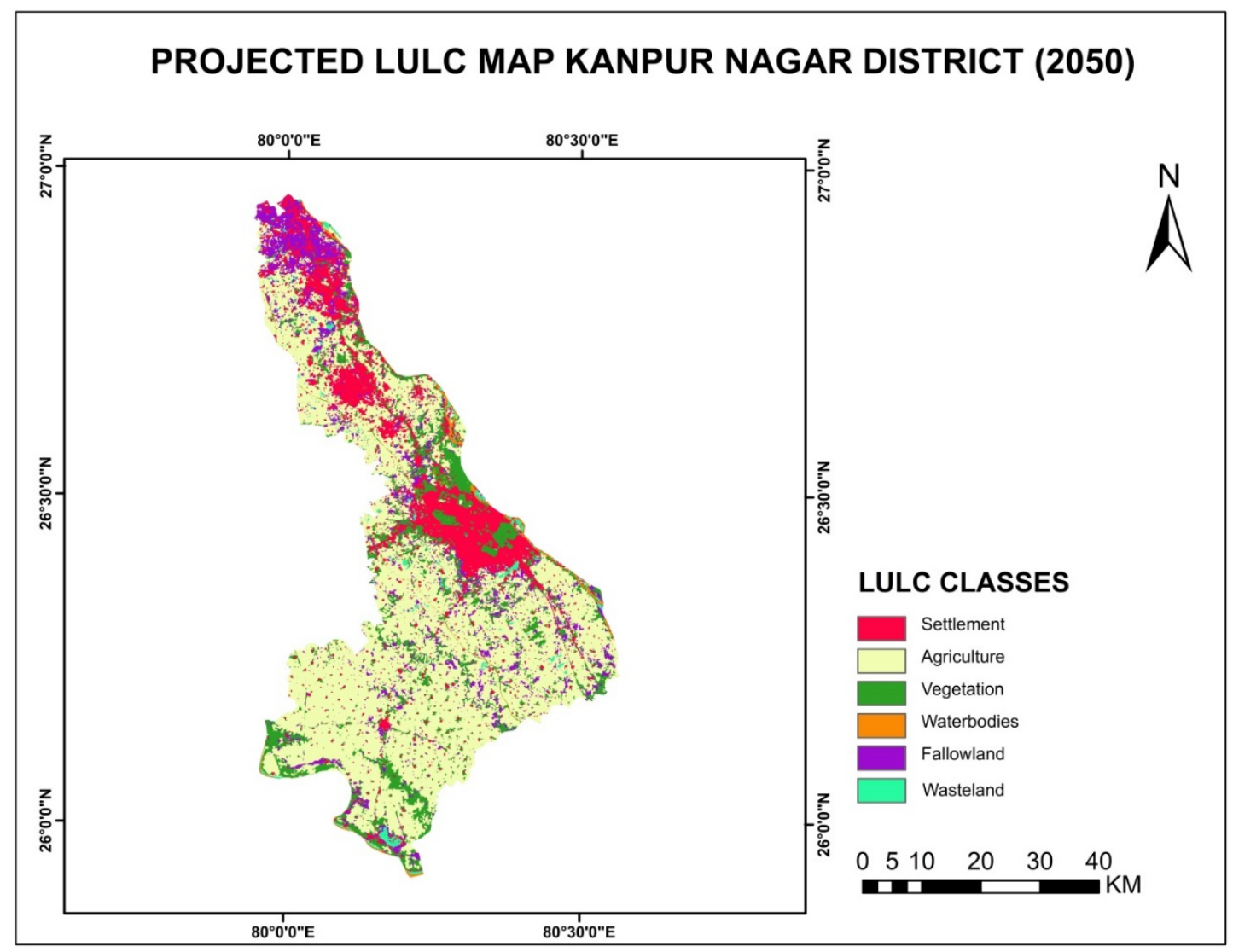

Figure 14. Projected land use and land cover map for year 2030 


\section{CONCLUSION}

The research study demonstrates GIS and remote sensing's ability to retrieve and analyses patio-temporal data. In this study, an attempt was to create a spatial database of LULC in the Kanpur Nagar district. For this, a comprehensive LULC map was created. For a total of 40 years, four distinct years were spent studying urbanization in the Kanpur Nagar district.

The research has shown that urbanization and spatiotemporal growth can be quantified and compared across time. Landsat data proved to be an adequate data source for evaluating Kanpur's growing and increasingly changing urban growth. In this study using the combined cellular automata and Markov chain model future changes of LULC have been predicted for 2050. LCM landscape changes in Idrisi Elva edition 17.0 for more than 30 years was measured. A transition probability matrix that depicts the transition from one class to another overall time intervals was generated. Multi-temporal Landsat images were used to generate LULC maps, which helps in the CA- Markov process to predict the future spatial and temporal changes of LULC. According to the simulation results, an increase in the settlement area by 114 sq. $\mathrm{km}$ from 2020 to 2050 is expected. In the case of various social phenomena in Kanpur, the spreading out of land use in an urban area continues to expand along with transport nodes and roads or other patterns. With the establishment of industries, uncontrolled migration to Kanpur city from multiple directions in terms of better employment options has expanded. Kanpur is one of India's most industrialized cities, and the city's better employment, education, as well as other services act as a pull factor for newcomers. These demographic and economic factors encourage spatial growth and allow the city to spread out into fertile agricultural land. Growing population growth places strain on existing resource bases, and Kanpur should have a master plan in place for at least the next 20 to 50 years. Because there is less scope for horizontal expansion of the city, planners and city developers should consider vertical expansion of the city.

\section{REFERENCES}

Anderson J.R, Hardy, E.E., Roach, J.T., Witmer, R.E: A Land Use and Land Cover Classification System for Use with Remote Sensor Data, Geological survey professional paper, United States Government printing office, Washington, 1976

Moghal A. A. B., Dafalla M. A., Elkady T. Y., and Al-Shamrani M.A., Lime Leachability Studies on Stabilized Expansive Semi-Arid Soil. International Journal of GEOMATE, Vol. 9, Issue 18, 2015, pp.1467-1471.

Awal ASMA, Hosseini H. and Hossain M.Z., Strength, Modulus of Elasticity and Shrinkage Behaviour of Concrete Containing Waste Carpet Fiber, International Journal of GEOMATE, Vol. 9, Issue 17, 2015, pp. 14411446.

Hossain M.Z., For Chapter in a Book, Soil Mechanics, 4th ed. Vol. 2, Sakai, Ed. Sankeisha Publisher's Name, Year, pp. 11-60.

Annan B., Unpublished Work but Accepted, Vol., Issue, Year.

Kimura S., Journal Paper Title, J. of Computer Science, Vol. 1, Issue 2, 1987, pp. 23-49.

Islam M.R., Conference proceedings, in Proc. 2nd Int. Conf. on GEOMATE, 2011, pp. 8-13.

Hossain M.Z. and Awal ASMA, Experimental Validation of a Theoretical Model for Flexural Modulus of Elasticity of Thin Cement Composite, Const. Build. Mat., Vol.25, No.3, 2011, pp.1460-1465. 